\title{
Amplitude-Frequency Effects of Y-cut Langanite and Langatate
}

\section{Yoonkee Kim}

\author{
U.S. Army Communications-Electronics Command \\ Research Development \& Engineering Center \\ Fort Monmouth, NJ, 07703
}

\begin{abstract}
Amplitude-frequency effects of a y-cut langanite (LGN) resonator and a y-cut langatate (LGT) resonator were measured. The frequency shifts from the baseline frequency with $1 \mathrm{~mA}$ were measured as a function of drive currents up to $28 \mathrm{~mA}$. While high drive current shifted the frequency, it also heated the crystal locally, causing temperature-related frequency changes. The local heat transfer and its influence on the frequency were analyzed. The amplitude-frequency shift was effectively measured, not affected by the temperature-related frequency changes. It is found that the $3^{\text {rd }}, 5^{\text {th }}$, and $7^{\text {th }}$ overtones (OT's) behave as soft springs, i.e., resonant frequency decreases as drive current increases. The drive sensitivity coefficients of the $3^{\text {rd }}$ and $5^{\text {th }}$ OT's are in the vicinity of $-2 \mathrm{ppm} /(\mathrm{current}$ density in $\left.\left[\mathrm{mA} / \mathrm{mm}^{2}\right]\right)^{2}$ or $-2 \mathrm{ppb} /(\mathrm{current} \text { in }[\mathrm{mA}])^{2}$ for both resonators. The $7^{\text {th }}$ OT's are higher than the other OT's: $-5 \sim-7$ $\mathrm{ppb} / \mathrm{mA^{2 }}$. The lowest drive sensitivity is $-1.2 \mathrm{ppb} / \mathrm{mA} A^{2}$ on the $5^{\text {th }}$ OT of the LGT.
\end{abstract}

\section{INTRODUCTION}

Due to a combination of very small acoustic loss (higher $Q$ than quartz) and temperature-compensated orientations for thickness-shear waves ( $c$ mode), single crystals of langanite $\left(\mathrm{La}_{3} \mathrm{Ga}_{5.5} \mathrm{Nb}_{0.5} \mathrm{O}_{14}\right.$ or $\left.\mathrm{LGN}\right)$ and langatate $\left(\mathrm{La}_{3} \mathrm{Ga}_{5.5} \mathrm{Ta}_{0.5} \mathrm{O}_{14}\right.$ or LGT) are expected to perform better than quartz in certain frequency control applications [1]. In order for resonator designers to realize precision resonators using these materials, a great deal of non-linear material properties need to be known in addition to the primary knowledge about the material constants (stiffness, piezoelectric, and dielectric) and the temperature-frequency coefficients. Some of the non-linear effects in a piezoelectric resonator are force-frequency, acceleration-frequency, resonance amplitude-frequency, intermodulation, mode coupling-activity dips, dynamic thermal-frequency, and film stress-frequency [2].

One of the non-linear effects is an amplitudefrequency effect where resonant frequency changes as a function of drive current due to nonlinear elastic constants of resonator crystal $[3,4]$. In quartz resonators, the amplitude-frequency effects may be adjusted by the design of the resonator such as crystal cut, contouring, and overtone [5]. A lower amplitude-frequency effect implies insensitivity to current fluctuations and slow current drift in an oscillator circuit, contributing in better short-term stability and lower long-term aging, respectively [6].

This paper presents measurements of amplitudefrequency effects for a $\mathrm{Y}$-cut langanite $\left(\mathrm{La}_{3} \mathrm{Ga}_{5.5} \mathrm{Nb}_{0.5} \mathrm{O}_{14}\right.$ or LGN) resonator and a Y-cut langatate $\left(\mathrm{La}_{3} \mathrm{Ga}_{5.5} \mathrm{Ta}_{0.5} \mathrm{O}_{14}\right.$ or LGT) resonator. To the best knowledge of the author, this is the first report on the amplitude-frequency effects of langasite isomorph (LGX) materials.

\section{MEASUREMENT METHODOLOGY}

Table 1 lists the parameters of the LGN and the LGT resonators investigated. The $3^{\text {rd }}, 5^{\text {th }}$, and $7^{\text {th }}$ overtone (OT) slow-shear modes (c modes) were measured. The resonators have parabolic frequency-temperature (F-T) characteristics with $65 \sim 75^{\circ} \mathrm{C}$ turnover temperatures [1].

Table 1. Resonator parameters.

\begin{tabular}{|c|c|c|c|c|}
\hline & Y-cut LGN & \multicolumn{2}{c|}{ Y-cut LGT } \\
\hline Crystal disk & \multicolumn{3}{|c|}{$\begin{array}{c}\text { Plano-convex } \\
14 \text { mm Ø }\end{array}$} \\
\hline Diopter & \multicolumn{3}{|c|}{3} & \multicolumn{2}{c|}{2} \\
\hline Electrodes & \multicolumn{2}{|c|}{$\begin{array}{r}6.35 \mathrm{~mm} \emptyset \text { gold with chrome } \\
\text { adhesion layer }\end{array}$} \\
\hline $\begin{array}{c}\text { Slow-shear } \\
\text { velocity }[\mathrm{m} / \mathrm{s}]\end{array}$ & 2859.36 & 2600.32 \\
\hline $3^{\text {rd }}$ OT $[\mathrm{MHz}, \Omega]$ & 6.047 & 3.5 & 6.149 & 3 \\
\hline $5^{\text {th }}$ OT $[\mathrm{MHz}, \Omega]$ & 10.082 & 6 & 10.254 & 5 \\
\hline $7^{\text {th }}$ OT $[\mathrm{MHz}, \Omega]$ & 14.102 & 12 & 14.347 & 11 \\
\hline
\end{tabular}

Fig.1 shows a schematic of the measurement setup, which was basically the same configuration as described in [6], except an oven was used here. A network analyzer (NA) was utilized as both a frequency source and a detector. The signal from the source was amplified and fed to a test resonator through a $\pi$ network, which was placed in a precision oven. In order not to overload the detector, the 
voltage across the load resistor was divided using two resistors. Calibration was performed with a following procedure: 1) Replace the test resonator with a $10 \mathrm{ohm}$ resistor, 2) Read the current $i$ with a current probe using an oscilloscope, and 3) Prorate the detector reading to match the voltage $\mathrm{v}$ and the current $\mathrm{i}$. There were also variations in phase by a few degrees over the test range of the source amplitude of the network analyzer. It was also accounted for during the measurements. The amplifier of the test circuit allowed current flow to a resonator up to $28 \mathrm{~mA}$ without distorting the output sinusoidal waveform.

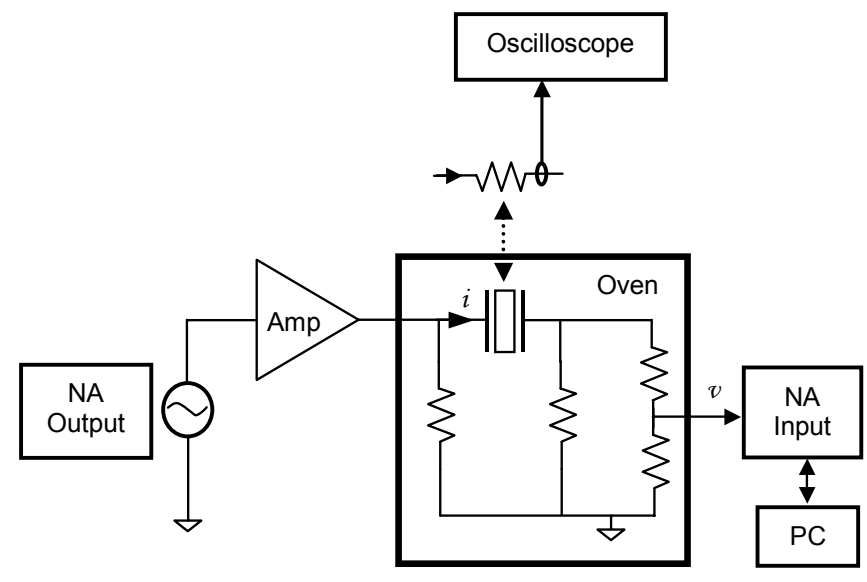

Figure 1. Measurement setup.

A few AT-cut and BT-cut quartz resonators were tested at room temperature before LGX samples in order to confirm the experimental setup. A hard spring effect for the AT-cut and a soft spring effect for the BT-cut were observed as in [7]. When LGX resonators were measured next, a substantially higher current than that for the quartz was needed to produce amplitude-frequency bending in resonance curves, indicating that the LGX resonators have significantly smaller amplitude-frequency effects than the quartz resonators tested. Furthermore, the frequency shifts were accompanied by temperature frequency changes due to local heating by the high current. Therefore, it was needed to measure only the amplitude-frequency effects, not affected by the temperature effects.

The measurement procedure was as follows: 1) Measure a reference phase $\phi_{o}$ of a resonant frequency $f_{o}$ at a low current $i_{L}(\sim 1 \mathrm{~mA})$. 2) Apply a high current $i_{H}$, continue frequency sweep until $f_{o}$ stabilizes while tracking $f_{o}$ with $\left.\phi_{o} .3\right)$ At onset of applying $i_{L}$, read $f_{o}$ to obtain a frequencyamplitude frequency change $\Delta \mathrm{f}_{\mathrm{A}-\mathrm{F}}$. 4) Repeat for test currents with both down and up frequency sweep direction. Fig. 2 shows how $f_{o}$ of an LGX resonator typically behaves during measurement. The current flow changes with a step from $i_{L}$ to $i_{H}$, then back to $i_{L}$ as shown in Fig. 2(a). (Strictly speaking, the step represents an NA output voltage. The current flow is not constant, but it peaks at a resonant fre- quency. Thereafter, it is interrupted by the rest period for frequency response data transfer/process. This repeats as many as the data points.) The resonator is initially placed at a temperature having a positive F-T slope (Fig. 2(b)) or a negative one (Fig. 2(c)). The frequency jumps $\Delta \mathrm{f}_{\mathrm{A}-\mathrm{F}}$ occur at the onsets of $i_{H}$ and $i_{L}$ and temperature frequency gradient $\Delta \mathrm{f}_{\mathrm{T}}{ }^{\prime}$ traces the $\mathrm{F}-\mathrm{T}$ slope while the resonator temperature increases during the $\mathrm{i}_{\mathrm{H}}$ period, then decreases during the $\mathrm{i}_{\mathrm{L}}$ period. The first $\Delta \mathrm{f}_{\mathrm{A}-\mathrm{F}}$ at $\mathrm{i}_{\mathrm{L}}-\mathrm{i}_{\mathrm{H}}$ and the second $\Delta \mathrm{f}_{\mathrm{A}-\mathrm{F}}$ at $\mathrm{i}_{\mathrm{H}}-\mathrm{i}_{\mathrm{L}}$ are expected to be same. However, at the onset of $\mathrm{i}_{\mathrm{H}}$, the resonance curve often distorted severely especially at high currents and it became a typical curve with a bend as $\mathrm{f}_{\mathrm{o}}$ stabilized, i.e. the resonator's temperature approached to equilibrium. Such distortion didn't occur at the onset of $i_{L}$. Thus, the second $\Delta \mathrm{f}_{\mathrm{A}-\mathrm{F}}$ was taken throughout the measurement. It was speculated that the difference in the two $\Delta \mathrm{f}_{\mathrm{A}}$ F's would be related to the dynamic stress changes inside the resonator, caused by the combination of the frequency sweep period and the rest period for transferring and processing the data. (This complicated stress change may affect the accuracy in measuring $\Delta \mathrm{f}_{\mathrm{A}-\mathrm{F}}$, but it is believed that it would be small comparing to $\Delta \mathrm{f}_{\mathrm{A}-\mathrm{F}}$. Analyzing the stress is beyond the scope of this paper and is not investigated further.)

The faster speed for a frequency sweep is more desirable to shorten the data-sampling interval. However, an overshooting measurement artifact occurs when the sweep speed is too fast [8]. Not to have such an artifact, two different speeds were selected for the $i_{H}$ and $i_{L}$ period: $5 \mathrm{sec}$ and $2 \mathrm{sec}$, respectively. The rest period between sweeps was approximately $1 \mathrm{sec}$.

(a)

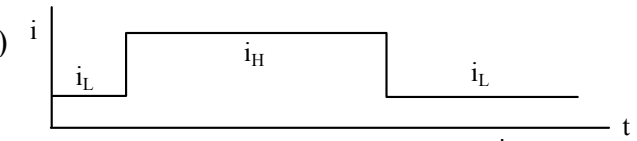

(b)

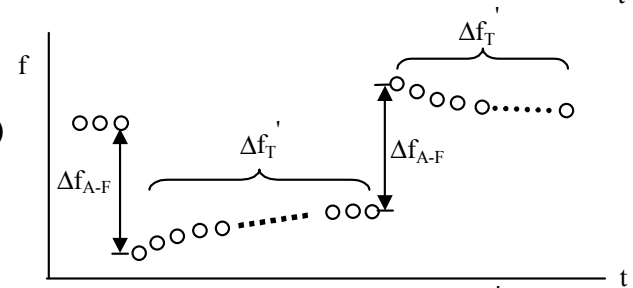

(c)

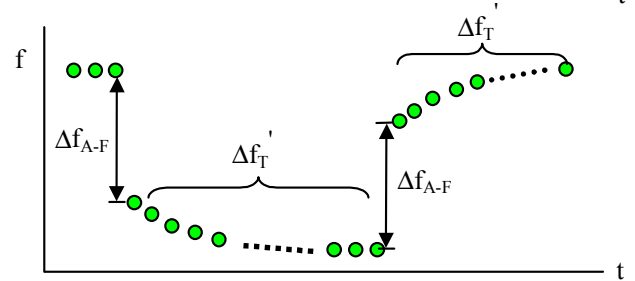

Figure 2. Resonant frequency excursion during measurements: (a) Step change in current magnitude, (b) For positive F-T slope, and (c) For negative F-T slope. 
In an effort to minimize the unwanted $\Delta \mathrm{f}_{\mathrm{T}}{ }^{\prime}$, the resonator was placed in a precision oven of which temperature was set slightly below the turnover (TO) temperature of the resonator. With the local heating by $\mathrm{i}_{\mathrm{H}}$, the temperature of the resonator would approach closer to its TO temperature, i.e. a lower F-T slope.

An F-T curve of an LGN resonator was measured and shown in Fig. 3. It shows a typical parabolic curve with a $73.5^{\circ} \mathrm{C}$ TO temperature. Using the method described above, the $\Delta \mathrm{f}_{\mathrm{A}-\mathrm{F}}$ of the LGN was measured for three different oven temperatures: a few degrees lower $\left(68{ }^{\circ} \mathrm{C}\right)$, a half degree lower $\left(73{ }^{\circ} \mathrm{C}\right)$, and a few degrees higher $\left(78{ }^{\circ} \mathrm{C}\right)$ than the TO temperature. The test current was maintained the same as $22 \mathrm{~mA}$ for the three measurements. Fig. 4 shows three plots of $f_{o}$ for the three temperatures. The magnitude, changing direction, and rate of $\Delta \mathrm{f}_{\mathrm{T}}$ reflects where the temperature of the resonator was on the F-T curve, as discussed for Fig. 2. The three measurements yielded an approximately same $\Delta \mathrm{F}_{\mathrm{A}-\mathrm{F}}$ value of $-1.8 \mathrm{ppm}$ regardless of the oven temperature. The deviation among the three was $0.3 \mathrm{ppm}$ and it would be filtered out by measuring many data points. By looking at the $73^{\circ} \mathrm{C}$ data, one may see that the local heating was less than $0.5^{\circ} \mathrm{C}$ since the frequency increase during the $\mathrm{i}_{\mathrm{H}}$ period and the decrease during the $i_{L}$ period indicates the temperature is still on the positive slope side of the F-T curve.

\section{LOCAL HEAT TRANSFER ANALYSIS}

The transient temperature of the resonator disk during the whole $\mathrm{i}_{\mathrm{L}}-\mathrm{i}_{\mathrm{H}}-\mathrm{i}_{\mathrm{L}}$ period is analyzed using a lump model [9]. During the $i_{H}$ period, starting from $t=0$, the temperature change of the resonator disk, $\Delta \mathrm{T}(\mathrm{t})$, is given by

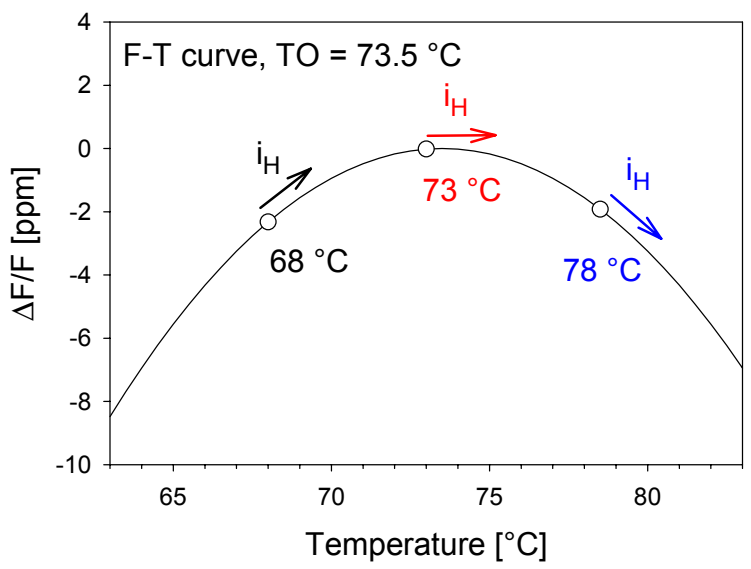

Figure 3. Parabolic F-T curve of the $5^{\text {th }}$ OT of an LGN and three oven temperatures. The TO temperature is $73.5^{\circ} \mathrm{C}$.

$$
\begin{gathered}
\Delta T(t)=P / G\left(1-e^{-t / \tau}\right) \\
\tau=C_{v} / G
\end{gathered}
$$

where $\mathrm{P}$ is the heat flow power, $\mathrm{G}$ is the thermal conductance (which represents mounting clips including radiation) to thermal ground (which represents the package), $\mathrm{C}_{\mathrm{v}}$ is the heat capacity of the resonator disk, and $\tau$ is the time constant. After sufficient time passes, $\Delta \mathrm{T}(\mathrm{t})$ reaches an equilibrium to $P / G$. Then, the current abruptly drops to $i_{L}$ at $t=t_{0}$. During the $\mathrm{i}_{\mathrm{L}}$ period, $\Delta \mathrm{T}(\mathrm{t})$ is given by

$$
\Delta T(t)=P / G e^{-\left(t-t_{0}\right) / \tau} .
$$

The heat capacity of the resonator disk is given by

$$
C_{v}=c_{p} \cdot \rho \cdot V
$$

where $c_{p}$ is the specific heat, $\rho$ is the mass density, and $V$ is the volume. The parameters used for the calculation are $c_{p}$ $=0.6$ joule $/ \mathrm{g} \cdot \mathrm{K}$ (for LGS) [10] and $\rho=5.934$ and 6.164 $\mathrm{g} / \mathrm{cm}^{3}$ for LGN and LGT, respectively [11]. For obtaining $\mathrm{V}$, the thickness was calculated from fundamental frequency using the acoustic velocity of the slow-shear mode, $2659.36 \mathrm{~m} / \mathrm{s}$ and $2600.32 \mathrm{~m} / \mathrm{s}$ for Y-cut LGN and Y-cut LGT, respectively [12]. The thickness variation of the sample due to contouring was ignored. Then, $\mathrm{C}_{\mathrm{v}}$ was calculated to be 0.42 joule $/ \mathrm{K}$ and 0.43 joule $/ \mathrm{K}$ for the $\mathrm{LGN}$ and the LGT, respectively. Because the two materials had similar values, further investigation was continued for the LGN only.

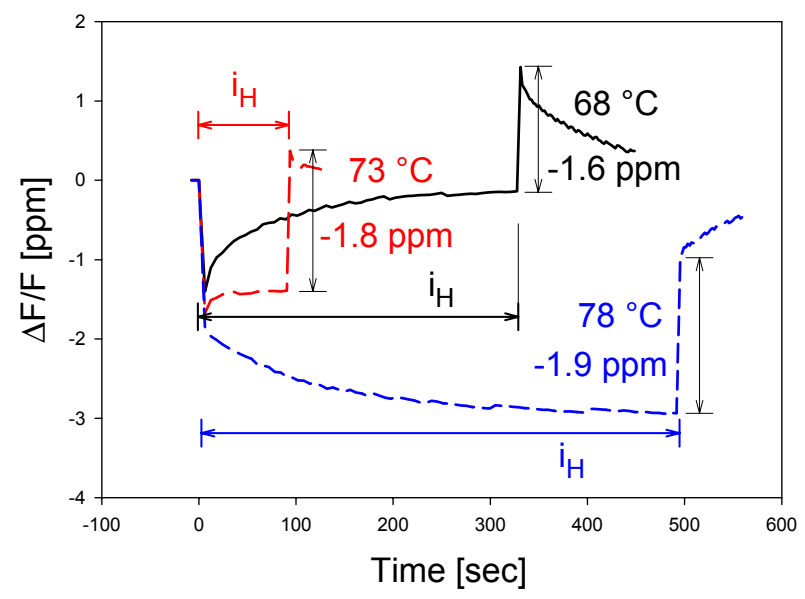

Figure 4. Measurements of amplitude-frequency effects at three oven temperatures. 
To obtain $\tau$ of the LGN resonator disk, a following experiment was performed: 1) Immerse the LGN resonator (the same one for the oven temperature experiment) in $62^{\circ} \mathrm{C}$ water, then wait for thermal equilibrium, 2) Rapidly immerse it into $0^{\circ} \mathrm{C}$ water. The trail of $\mathrm{f}_{\mathrm{o}}$ was recorded during this abrupt temperature change, 3 ) Convert $f_{o}$ response to $\Delta \mathrm{T}(\mathrm{t})$ using the quasi-static $\mathrm{F}-\mathrm{T}$ curve. This direct conversion is possible only if the thermal transient effects on $f_{o}$ are negligibly small. Fig. 5 shows the $\mathrm{f}_{\mathrm{o}}$ response and its conversion to $\Delta \mathrm{T}(\mathrm{t})$. One can see a minor deviation from an exponentially decaying curve at the initial frequency changes. It's not believed to be a transient effect, but the parabolic F-T characteristic is responsible for it, evidenced by that its converted temperature gradient is an exponential curve. Note that the frequency response approaches to equilibrium without a noticeable overshoot, indicating the resonator behaves more like an SC-cut quartz rather than an AT-cut quartz [7]. This can be explained by the fact that the LGX has very small values of both a force-frequency coefficient and a coefficient of planar-stress [13].

By fitting the $\Delta \mathrm{T}(\mathrm{t})$ data to Eq. $(2), \tau$ can be obtained. However, Eq.(4) [14] is more convenient to use than Eq.(2),

$$
\frac{\Delta T(t)-T_{f}}{T_{i}-T_{f}}=e^{-t / \tau}
$$

where $\mathrm{T}_{\mathrm{i}}=62{ }^{\circ} \mathrm{C}$ and $\mathrm{T}_{\mathrm{f}}=0{ }^{\circ} \mathrm{C}$. The time constant of the system obtained was $125 \mathrm{sec}$. Thus, $\mathrm{G}$ was calculated to be $2.85 \mathrm{~mW} / \mathrm{K}$.

To estimate the power dissipation, the following assumptions were made: 1) Resonator resistance: $6 \mathrm{ohm}$. 2) Current: $18.6 \mathrm{~mA}$. [This is the calculated average value from the measurement for $22 \mathrm{~mA}$ at $\mathrm{f}_{\mathrm{o}}$, considering the frequency sweep period $(5 \mathrm{sec})$ and the rest period $(1 \mathrm{sec})$.] The temperature increase $\Delta \mathrm{T}[=\mathrm{P} / \mathrm{G}$ from Eq.(1)] is $0.73 \mathrm{~K}$.

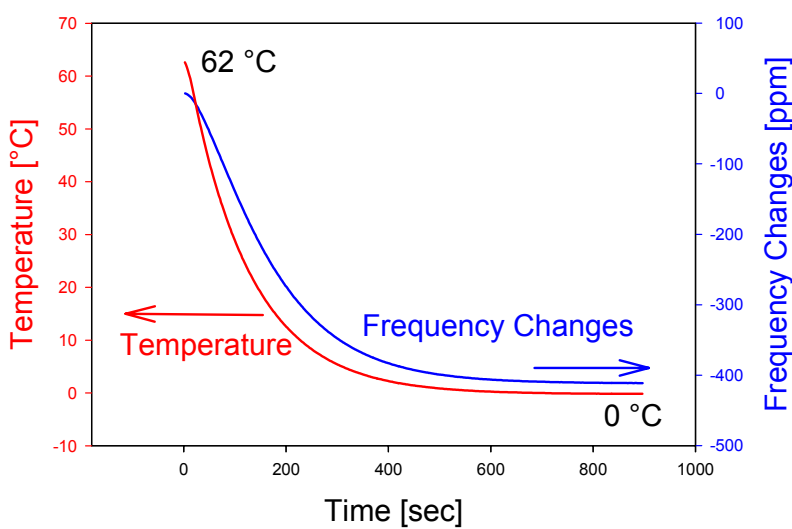

Figure 5. Measured frequency response of an LGN resonator and its converted temperature gradient for the rapid immersion from $62^{\circ} \mathrm{C}$ water to $0^{\circ} \mathrm{C}$ water.
Now, assume $\Delta \mathrm{T}=1 \mathrm{~K}$ and the ambient temperature $=$ $63{ }^{\circ} \mathrm{C}$. This heat energy starts to dissipate at the onset of $\mathrm{i}_{\mathrm{L}}$. Using Eq. (3), the $1 \mathrm{~K}$ heat energy dissipation is calculated. The temperature gradient and its corresponding frequency response for the initial $200 \mathrm{sec}$ period are shown in Fig. 6. The $1 \mathrm{~K}$ heat causes $1.7 \mathrm{ppm}$ in $\Delta \mathrm{F} / \mathrm{F}$. Within the first 4 sec, $0.03{ }^{\circ} \mathrm{C}(0.05 \mathrm{ppm})$ drops. The measurement of $\Delta \mathrm{F}_{\mathrm{A}-\mathrm{F}}$ takes about $3 \mathrm{sec}$ from the end of $\mathrm{i}_{\mathrm{H}}$. Thus, one can see that the measurement of $\Delta \mathrm{F}_{\mathrm{A}-\mathrm{F}}$ is fast enough to beat $\Delta \mathrm{f}_{\mathrm{T}}{ }^{\prime}$. This analysis also agrees with the results of the three-oventemperature measurement. The rest of the LGX resonators were measured with the oven temperature's setting at $63^{\circ} \mathrm{C}$.

\section{DRIVE SENSITIVITY}

The measurements were repeated for the current up to $28 \mathrm{~mA}$. Fig. 7 shows the measured magnitude and phase of the $7^{\text {th }}$ OT of an LGN as a function of the driving voltage, i.e. network analyzer output. As the current increases, the resonance curves bend toward a lower frequency. Phase also shifts downward correspondingly. The change in magnitude and phase shape implies the motional impedance of the resonator also changes. Note that an abrupt current jump occurs at the driving voltage of $200 \mathrm{mV}$. When such a jump occurs, the phase becomes steep and obviously the resonant frequency deviates from the typical trend in the frequency bending, represented by the following Eq. (5).

Fig. 8 shows an unusual resonance curve with an anharmonic mode interference, which is a catastrophe for a resonator. In this case, the severely distorted phase makes measuring $\mathrm{f}_{\mathrm{o}}$ impossible. All the measured $\Delta \mathrm{F}_{\mathrm{A}-\mathrm{F}}$ data except such abrupt current jump cases or mode interference cases were collected for obtaining drive sensitivities.

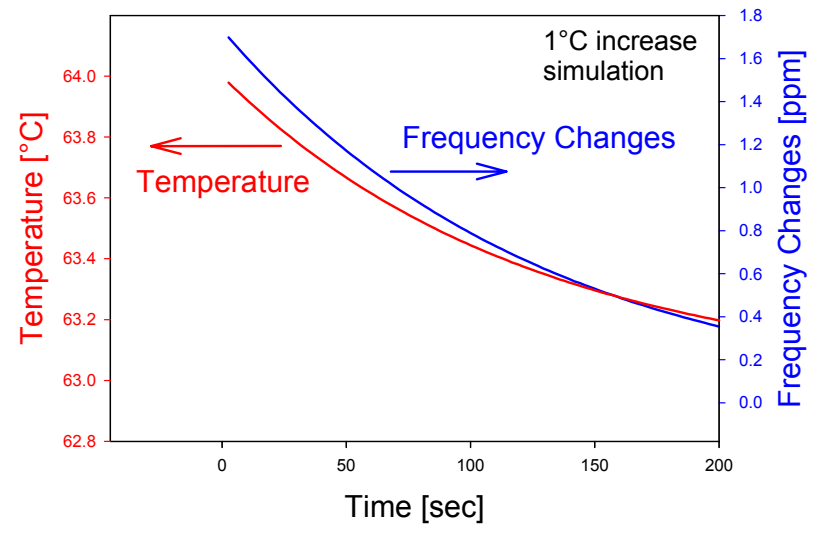

Figure 6. Estimated temperature and frequency changes of an LGN resonator when $1{ }^{\circ} \mathrm{C}$ heat energy dissipates. The ambient temperature is $63^{\circ} \mathrm{C}$. 

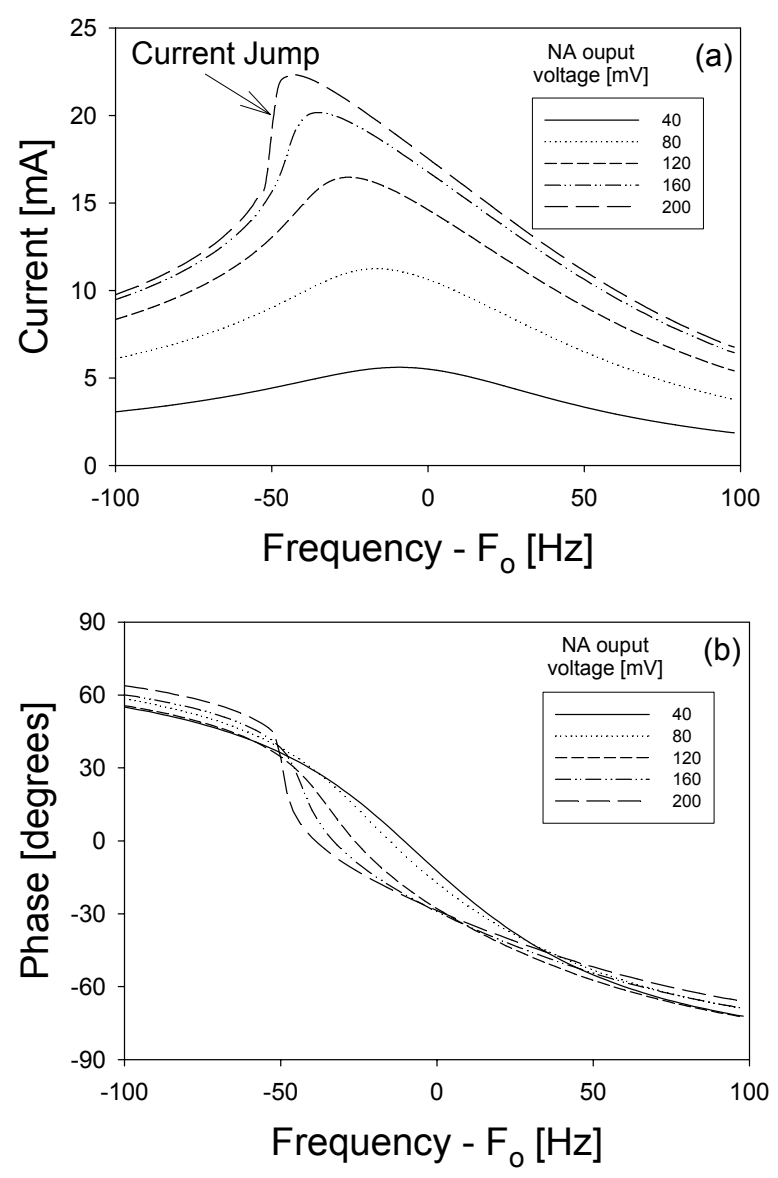

Figure 7. Typical measured data and curve as a function of network analyzer output voltage- (a) Current magnitude, (b) Phase.

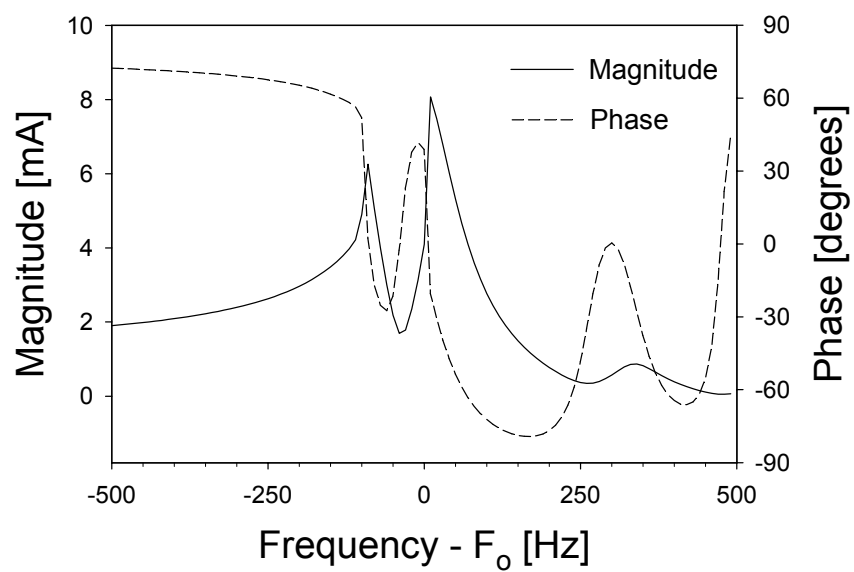

Figure 8. Anharmonic mode interference causes distortion in magnitude and phase.
Fig. 9 shows typical frequency-versus-current data of the $3^{\text {rd }}, 5^{\text {th }}$, and $7^{\text {th }}$ OT of the LGN and the LGT with down and up sweep. The two sweeps produced very similar curves for each OT. The data set of each OT and each sweep was fitted with a quadratic curve to obtain a drive sensitivity coefficient D defined by [6]

$$
\Delta F_{A-F} / F=D \cdot i^{2}
$$

For each OT, the average value of the D's of the two sweeps was taken. For the fundamental modes, instead of showing a quadratic characteristic, the $\Delta \mathrm{F}_{\mathrm{A}-\mathrm{F}}$ data points were scattered within $\pm 0.5 \mathrm{ppm}$ (implying that the $\mathrm{D}$ of the fundamental modes would be similar to or even smaller than the D's of the OT's), due to measurements of noisy reference frequencies at $i_{L}$. ( $Q$ was $2 \sim 3 \times 10^{5}$ for the fundamental modes and at least one order higher for the OT's for both materials.) Thus, it was not possible to obtain D for the fundamental modes.
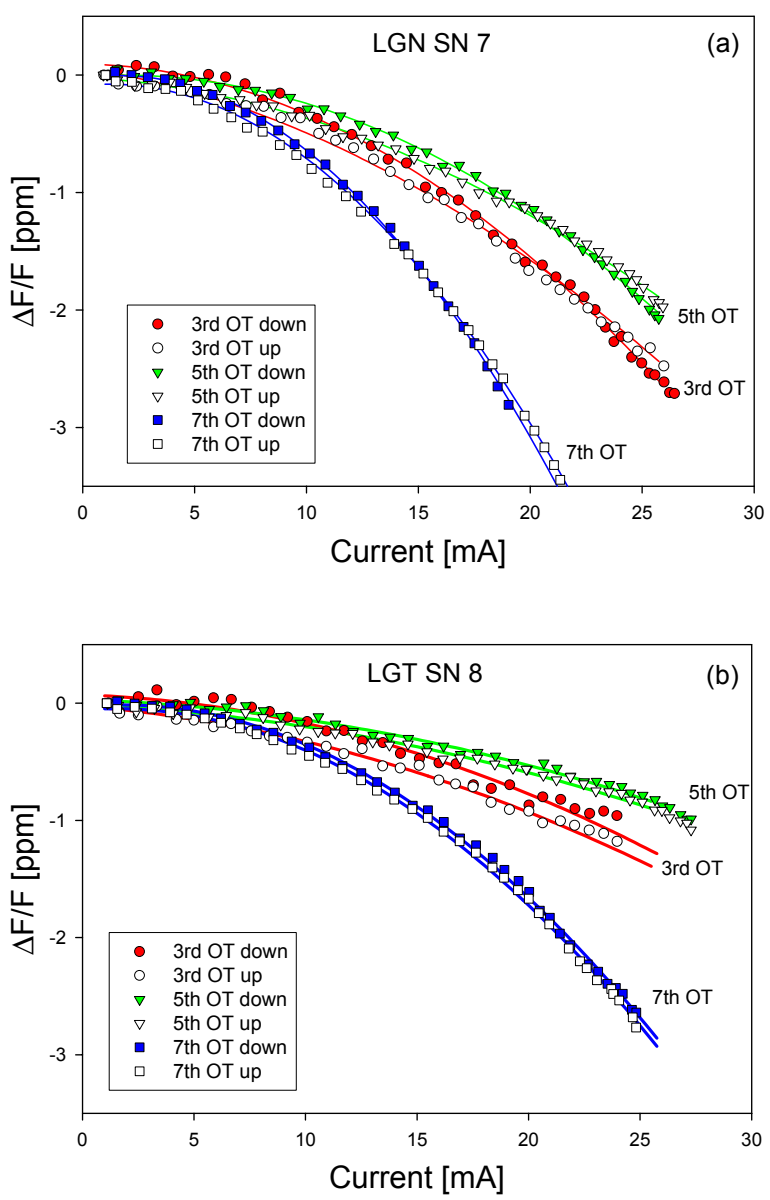

Figure 9. Mode frequency changes versus currents at resonant frequencies of (a) LGN, (b) LGT. Curve-fit to measured data of down and up sweep frequencies are shown as solid lines. 
Three of each LGN and LGT resonator were measured and the results are listed in Table 2. Obtaining D for the $7^{\text {th }}$ OT of SN10 was not possible either, due to the anharmonic mode interference as shown above. The drive sensitivity coefficients of the $3^{\text {rd }}$ OT's and the $5^{\text {th }}$ OT's are in the vicinity of $-2 \mathrm{ppb} /(\text { current in }[\mathrm{mA}])^{2}$ or $-2 \mathrm{ppm} /$ (current density in $\left.\left[\mathrm{mA} / \mathrm{mm}^{2}\right]\right)^{2}$ for both resonators (Note that (electrode area $)^{2} \sim 1000 \mathrm{~mm}^{4}$ ). The $5^{\text {th }}$ OT's have slightly lower $\mathrm{D}$ than the $3^{\text {rd }}$ OT's. The $7^{\text {th }}$ OT's have higher D than the other OT's. The lowest drive sensitivity is $-1.2 \mathrm{ppb} / \mathrm{mA}^{2}$ on the $5^{\text {th }}$ OT of the LGT. Overall, the LGT has smaller D than the LGN. It's not clear that the difference is due to contour or material properties. Measurements with various contours will clarify that.

Table 2: Drive sensitivity coefficient D of LGN and LGT. (SN is an arbitrary serial number and Avg is the average value of 3 resonators.) Obtaining $\mathrm{D}$ for $7^{\text {th }}$ OT of SN10 was not possible due to anharmonic mode interference.

\begin{tabular}{|c|c|c|c|}
\hline \multicolumn{5}{|c|}{ LGN } \\
\hline SN & $3^{\text {rd }}$ OT & $5^{\text {th }}$ OT & $7^{\text {th }}$ OT \\
\hline 6 & -3.85 & -2.65 & -6.85 \\
\hline 7 & -3.30 & -2.94 & -8.66 \\
\hline 10 & -3.15 & -2.66 & - \\
\hline Avg & -3.43 & -2.75 & -7.76 \\
\hline \multicolumn{4}{|c|}{ LGT } \\
\hline SN & $3^{\text {rd }}$ OT & $5^{\text {th }}$ OT & $7^{\text {th }}$ OT \\
\hline 8 & -1.65 & -1.06 & -4.91 \\
\hline 26 & -1.50 & -1.25 & -5.68 \\
\hline 28 & -1.74 & -1.19 & -5.47 \\
\hline Avg & -1.63 & -1.17 & -5.35 \\
\hline
\end{tabular}

\section{CONCLUSIONS}

This is the first published amplitude-frequency data for LGN and LGT resonators, to the best of the author's knowledge. The frequency shifts from the baseline frequency with $1 \mathrm{~mA}$ were measured as a function of drive currents up to $28 \mathrm{~mA}$. It is found that the $3^{\text {rd }}, 5^{\text {th }}$, and $7^{\text {th }}$ OT's behave as soft springs, i.e., resonant frequency decreases as drive current increases. The drive sensitivity coefficients of the $3^{\text {rd }}$ and $5^{\text {th }}$ OT's are in the vicinity of -2 $\mathrm{ppm} /\left(\text { current density in }\left[\mathrm{mA} / \mathrm{mm}^{2}\right]\right)^{2}$ or $-2 \mathrm{ppb} /$ (current in $[\mathrm{mA}])^{2}$ for both resonators. The $7^{\text {th }}$ OT's are $-5 \sim-7$ $\mathrm{ppb} / \mathrm{mA}^{2}$. The lowest drive sensitivity is $-1.2 \mathrm{ppb} / \mathrm{mA}^{2}$ on the $5^{\text {th }}$ OT of the LGT. Combined with the high Q of the material, the LGX has a potential for good short-term stability and low long-term aging. In addition, a thermal shock experiment reveals that the LGX behaves like an SC-cut quartz, i.e. an overshoot isn't noticeable in its frequency response.

\section{ACKNOWLEDGMENTS}

The author thanks Drs. R. Filler, J. Vig, and A. Ballato of US Army CECOM for many helpful discussions. Piezo Technology Inc., Orlando, FL, provided the resonators under US Army Contract N66001-97-C-8634.

\section{REFERENCES}

[1] R. C. Smythe, R. C. Helmbold, G. E. Hague and K. A. Snow, "Langasite, langanite and langatate bulk-wave Y-cut resonators," IEEE Trans. Ultrason. Ferro. Freq. Contr., Vol. 47, no. 2, pp. 355-360, 2000.

[2] A. Ballato, E. P. EerNisse, and T. Lukaszek, "The forcefrequency effect in doubly rotated quartz resonators," Proc. $31^{\text {st }}$ Annu. Symp. Freq. Contr., pp. 8-16, 1977.

[3] D. Hammond, C. Adams, and L. Cutler, "Precision crystal units," Proc. $17^{\text {th }}$ Annu. Symp. Freq. Contr., pp.215-232, 1963.

[4] J. J. Gagnepain and R. Besson, Nonlinear effects in piezoelectric quartz crystals, in W. P. Mason and R. N. Thurston, Physical Acoustics Vol. XI, pp. 245-288, 1975.

[5] J. A. Kusters, "The SC cut crystal - An overview," Proc. Ultrason. Symp., pp. 402-409, 1981.

[6] R. L. Filler, "The amplitude-frequency effect in SC-cut resonators", Proc. 39 ${ }^{\text {th }}$ Annu. Symp. Freq. Contr., pp.311-316, 1985.

[7] A. Ballato, Ch 3. Piezoelectric Resonators, in B. Parzen, Design of Crystal and Other Harmonic Oscillators, John Wiley \& Sons, NY, 1983.

[8] J. Marique, "The response of RLC resonant circuits to EMF of sawtooth varying frequency," Proc. I.R.E., pp.945-950, 1952

[9] G. C. M. Meijer and A. W. van Herwaarden, Thermal Sensors, Institute of Physics Publishing, Bristol and Philadelphia, 1994.

[10]Z. Wang, X. Cheng, D. Yuan, L. Pan, S. Guo, D. Xu, and M. $\mathrm{Lv}$, "Crystal growth and properties of $\mathrm{Ca}_{3} \mathrm{NbGa}_{4} \mathrm{Si}_{2} \mathrm{O}_{14}$ single crystals,” J. Crystal Growth, Vol. 249, pp.240-244, 2002.

[11] B. V. Mill, A. V. Butashin, G. G. Khodzhabagyan, E. L. Belokoneva, and A. N. V. Belov, "Modified rare-earth gallates with a $\mathrm{Ca}_{3} \mathrm{Ga}_{2} \mathrm{Ge}_{4} \mathrm{O}_{14}$ structure", Sov. Phys. Dokl., pp. 434-437, 1982.

[12] D. C. Malocha, M. P. da Cunha, E. Adler, R. C. Smythe, S. Fredric, M. Chou, R. Helmbold and Y. S. Zhou, "Recent measurements of material constants versus temperature for langatate and langanite," Proc. 2000 IEEE Int. Freq. Con. Symp., pp. 200-205, 2000.

[13] Y. Kim and A. Ballato, "Force-frequency effects of y-cut langanite and y-cut langatate," Proc. 2002 IEEE Int. Freq. Con. Symp., pp. 328-332, 2002.

[14] J. P. Holman, Heat Transfer, McGraw-Hill, NY, 1968. 